\section{Kidney \\ Blood Pressure Research}

\title{
The Association of Echocardiographic Peak Systolic Strain Rate with Cardiovascular Outcomes in Haemodialysis Patients
}

\author{
John Hughes Darren Green Diana YY Chiu Nik Abidin Philip A Kalra \\ Department of Renal Medicine, Salford Royal NHS Foundation Trust, Salford, UK
}

\section{Key Words}

Haemodialysis $\bullet$ Mortality $•$ Cardiovascular $•$ Echocardiography $\bullet$ Strain rate

\begin{abstract}
Background/Aims: Echocardiographic abnormalities of systolic function can be detected earlier with advancing echocardiographic technologies. Given the high prevalence of left ventricular hypertrophy in dialysis patients, we hypothesised that one such marker of strain, peak systolic strain rate (SR) would demonstrate association with cardiovascular outcome in a haemodialysis cohort. Methods: Recruited prevalent haemodialysis patients underwent standard transthoracic echocardiography as part of a detailed cardiovascular assessment on a non-dialysis day during a short inter-dialytic midweek break. Patients were followed up to mortality and cardiovascular end points. Multivariate Cox proportional hazard models were built to determine the association of above versus below median SR in a model adjusted for confounding factors. Results: 183 patients were enrolled and followed up for a median 925 days. Median age was 64.9 years, prevalence of LVH 55\%, and median SR -0.86 (-1.00 to -0.72 ). An SR greater than $-0.86 \mathrm{~S}^{-1}$ (less negative) had a hazard ratio (HR) of 2.32 (1.36 to 3.95) in association with all-cause mortality after adjustment for $\mathrm{EF}$, age, smoking history, $\mathrm{MI}$, previous transplant, albumin and systolic blood pressure. For cardiovascular mortality, the HR was 2.343 ( 0.99 to 5.553$) \mathrm{p}=0.046$. The only echocardiographic parameter independently associated with MACE was above median E/e (HR 2.09 [1.03 to 4.24], $p=0.04$ ). No echocardiographic parameter was associated with heart failure episodes. Conclusion: SR demonstrates association with outcome in this population and highlights the consideration that such subclinical cardiac changes should be routinely sought when referring haemodialysis patients for cardiac assessments.




\section{Kidney Blood Pressure Research}

Hughes et al.: Strain Rate in Dialysis Patients

\section{Introduction}

Cardiovascular mortality is the leading cause of death in patients with end stage renal disease (ESRD) [1]. Approximately $50 \%$ of all deaths in this cohort are from cardiovascular causes $[2,3]$. Atherosclerosis contributes to $61.5 \%$ of cardiovascular deaths in some studies and is widely prevalent at post mortem and during angiography [3-12]. However, a significant proportion of cardiovascular deaths does not relate to atherosclerosis [3, 13-15]. At initiation of haemodialysis, $74 \%$ of patients have left ventricular hypertrophy (LVH). A $1 \mathrm{~g}$ per month rise in LVMI has been shown to associate with a $62 \%$ increase in mortality [16]. Diastolic dysfunction and left atrial dilatation are also highly prevalent $[17,18]$, and $87 \%$ of patients have normal ejection fraction. Cardiovascular morbidity remains high in this population with preserved systolic function $[19,20]$. Because of this, the mathematical tools devised from the Framingham cohort to predict mortality in the general population do not identify renal patients at a high cardiovascular risk [21,22].

This has driven the search for novel biomarkers of adverse cardiovascular outcomes in this population. Much interest has been around the use of non-invasive imaging modalities such as echocardiography to derive such biomarkers. A novel application of the traditional 2D echocardiogram is speckle tracking echocardiography (STE). STE is an offline analysis of the 2D echocardiogram tracks acoustic speckles through the left ventricle myocardial wall $[23,24]$. The change in distance between the acoustic speckles between frames gives a value of the deformation of the myocardium at that point, termed "strain" and which is represented as a percentage. The rate of displacement of the acoustic speckles can also be quantified and this is termed "strain rate" (represented as $\mathrm{S}^{-1}$ ) [24]. Strain is most commonly quantified in the longitudinal vector, and the average strain in all segments in the longitudinal vector is termed Global Longitudinal Strain (GLS) [25]. We have previously described the association of GLS with outcome in an ESRD cohort. As well as average values for strain, the peak GLS is the maximum deformation during the cardiac cycle. The peak rate of myocardial deformation during systole can be represented as the peak global systolic strain rate (SRs) [26].

In patients with diabetes, a lower peak systolic strain rate (SRs) was observed when compared to age, sex matched controls $\left(-0.99 \mathrm{~S}^{-1}+/-0.17\right.$ compared to $-1.07 \mathrm{~S}^{-1}(+/-0.13)$, $\mathrm{p}=0.009 .{ }^{3}$ In patients who have recently had a myocardial infarction, the SR is lower compared to controls $[27,28]$. To date, no studies have looked at systolic strain rate imaging in haemodialysis patients.

The aim of this study was to determine whether SRs show independent association with outcomes in an ESRD population, in a multivariate model which includes conventional echocardiographic parameters. End points selected were all-cause mortality, cardiovascular mortality, major adverse cardiac events (MACE), and hospital admission for heart failure.

\section{Materials and Methods}

This study used the "CRISIS-HD" cohort from the Salford Kidney Study (SKS). This cohort has been described in detail previously [29]. The study complies with the declaration of Helsinki and local ethical approval was obtained (current UK REC reference 15/NW/0818).

Adult maintenance haemodialysis patients at Salford Royal NHS Foundation Trust or one its 4 satellite Units are approached for inclusion. If written, informed consent is obtained, patients undergo cardiovascular assessment including SKS study specific extended protocol echocardiography, as well as detailed data collection relating to co-morbidity, medication, acute event, laboratory sampling, and dialysis prescription. Death and cause of death data are obtained from the Office of National Statistics. Other end point event data, including MACE events, are obtained from patient self-reporting, review of Trust electronic patient records, and from the patients' GPs. Cardiovascular events or death were defined as those due to myocardial infraction, arrhythmia, heart failure, sudden cardiac death, and cerebrovascular accident. 


\section{Kidney Blood Pressure Research}

\section{Echocardiography}

All transthoracic echocardiography was performed on a non-dialysis day during a short inter-dialytic break. All patients were assessed in the left lateral decubitus position, using Philips echocardiography equipmentwith 3.5 MHz transducers with m-mode,2D echocardiographic capabilities [29,30]. Measurements were obtained according to published guidelines by the European Society of Echocardiography. Digital Loops were saved on the Phillips Xcelera image management system for offline analysis. Speckle tracking echocardiography for calculation of global longitudinal strain (GLS) was performed using QLAB cardiac motion quantification software. EF was calculated using the Biplane method as recommended by the ESC. ${ }^{31} \mathrm{LV}$ mass was calculated using 2D linear measurements and the Devereux formula, and indexed to height $^{2.7}[29,31]$.

All STE analysis was performed offline by JH and DC. Global longitudinal strain was calculated for each of the 2 chamber, 3 chamber and 4 chamber images. If one apical view was unavailable, then GLS was averaged over the available apical views. GLS was calculated by the user placing a mark either side of the mitral valve annulus in the end diastolic window and in the apical myocardium. The cardiac motion quantification software automatically identifies the endocardial border and creates a region of interest (where acoustic speckles will be tracked) extending to the epicardial border. If the region of interest does not fit, then it can be adjusted by the user. Tissue motion in this region of interest (ROI) is tracked throughout the cardiac cycle. The cardiac motions quantification software was used to calculate strain in each region of the myocardium in each 2 chamber, 3 chamber and 4 chamber view. Tracking can be viewed by the operator and in instances where tracking is inadequate the ROI can be adjusted or the segment excluded. The output is as a waveform of average global longitudinal strain GLS as shown in (Fig. 1) or as a strain rate curve which displays the rate of deformation during the cardiac cycle. The peak GLS is the most negative value obtained during systole. The peak systolic strain rate SRs is the most negative value on the rate/time curve during systole. GLS is expressed as a percentage change in the longitudinal dimension and therefore is given as a $\%$ and as a negative value [24]. Systolic strain rate is given as a negative value as it is rate of change in a negative direction and is given as $\mathrm{S}^{-1}$.

To assess the reproducibility of the assessment, a randomly selected cohort of echo images were re-analysed by $\mathrm{JH}$ to determine intra-user variability. To assess inter-user variability $\mathrm{DC}$ and $\mathrm{JH}$ independently analysed the whole cohort. Obtained values were compared using a Bland Altman analysis. The intra-observer variability for GLS had a bias of -0.68 with a standard error of 2.31 with limits of agreement (LOA) of -5.21 to 3.85 ( $\mathrm{n}=$ 44). 176 measures were compared for inter user variability and this had bias of -1.41 standard error of 4.62 with limits of agreements -10.5 to 7.7. The Bland Altman plots are shown in Supplementary Fig. 1 (for all supplementary material see www. karger.com/doi/xxx).

\section{Statistical analysis}

Statistical analysis was performed using R [32]. Normality was determined using the shapiro-wilk test, using the shapiro package, $<0.05$ indicating nonnormal distribution. To compare means from two normally distributed populations, un-paired t-tests were used. To compare

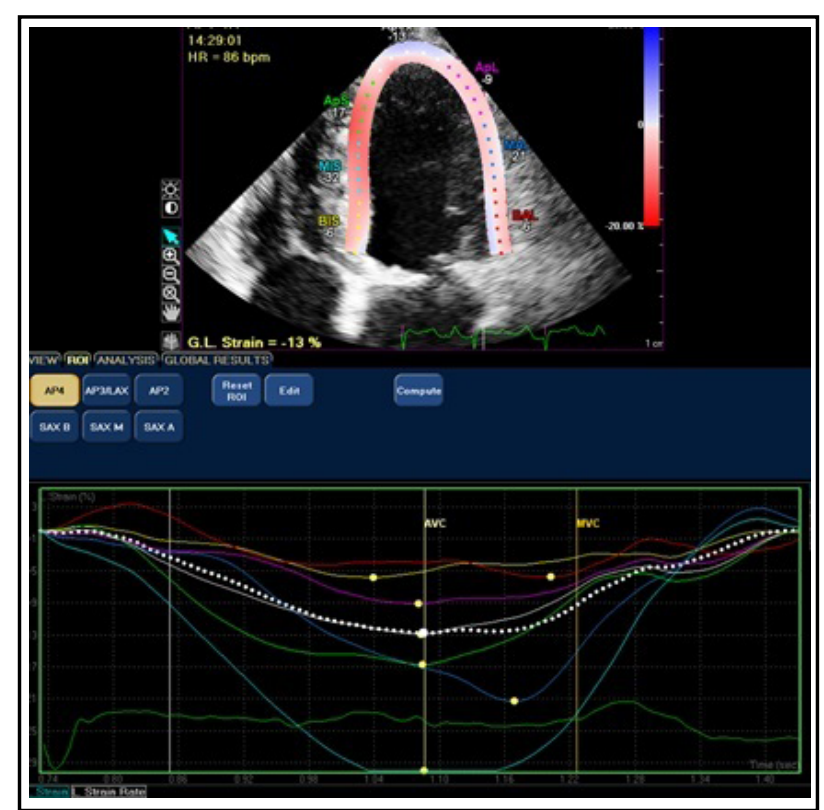

Fig. 1. Example of speckle tracking echocardiography. Four chamber view. Top half of image shows left ventricular myocardium and region of interest. Peak systolic strain demonstrated in each segment. Graph below shows longitudinal strain in each segment and overall global longitudinal strain (white dotted line) and tracking of all other segments in coloured lines. 


\section{Kidney Blood Pressure Research}

medians from two non-normally distributed populations, Wilcoxon test was performed. Fischer exact test was used to compare categorical variables.

Cox proportional hazards ratio was used for survival analyses. Follow up was from date of echocardiography. End points were all-cause mortality, cardiovascular mortality, MACE, and hospital admission for heart failure. Parameters that were significant on univariate analysis were included in a multivariate model. For the purpose of this analysis, all patients that were still alive and had not suffered a major adverse cardiac event were right censored at the point of transplantation, transfer out of area, or $31^{\text {st }}$ August 2016. For non-normal continuous variables, Log transformation was used. Hazard Ratio (HR) for outcomes were calculated using survival package in $\mathrm{R}$.

\section{Results}

435 patients were receiving in centre haemodialysis at the start of recruitment. Of these, 263 fulfilled the inclusion criteria. Written, informed consent was obtained from 219, who then underwent a first-year echocardiogram. At the study end, complete data were available for 183 patients. Supplementary Fig. 2 shows the study consort chart. Patients were followed up for a median of 925 days. 7 patients were lost to follow up, and censored at the point of last contact. 2 patients had an unknown cause of death. 40 patients received a renal transplant and were right censored at that point.

The baseline demographics of the final 183 patients are demonstrated in Table 1. Of note, there was a median age of 64.9 years, with a median time on dialysis of 1.39 years. 95 $\%$ of patients dialysed through a fistula, $67.8 \%$ were male and $14 \%$ had a prior diagnosis of heart failure. Median left ventricular mass was $50.6 \mathrm{gm}^{2.7}$, and the prevalence of $\mathrm{LVH}$, was 54.9 \%. Data for Global Longitudinal Strain (GLS) and peak systolic strain rate (SRs) were available for 178 of the 183 patients, with a median GLS of $-14 \%(-12.8$ to -16$)$ and median SR of -0.86 (-1.00 to -0.72 ). There was a significantly higher (less negative) peak systolic strain rate in patients who died $\left(-0.81 \mathrm{~S}^{-1}[-0.92\right.$ to -0.67$\left.]\right)$ compared to survivors $\left(-0.88 \mathrm{~S}^{-1}[-1.03\right.$ to -0.77$]), p=0.002$. There was a lower prevalence of preserved $\mathrm{EF}$ in patients who died $(69.4 \%$ compared to $85.2 \%, p=0.01$ ). GLS did not differ between those who died and those who survived.

Overall, 62 patients died, giving a mortality rate of 14.0 per 100 patient years at risk. The baseline demographics were compared between those patients who were alive at the end of the study period and those who were not, Table 1. Twenty four died from cardiovascular causes giving a cardiovascular mortality rate of 5.4 per 100 patient years at risk. 53 patients suffered a MACE giving an incidence rate of $14.1 \%$ per 100

Table 1. Baseline study characteristics, overall and divided according to survival status. Data are presented as mean (sd), median (IQR) or $n$ (\%). $\mathrm{UF}=$ Ultrafiltration Volume. $\mathrm{BP}=$ Blood pressure. $\mathrm{CRP}=\mathrm{C}$ reactive protein. $\mathrm{CCF}=$ Congestive Cardiac Failure. $\mathrm{MI}=$ Previous Myocardial Infraction, PVD = Previous Peripheral vascular disease. B.S.A. Body surface area. ${ }^{*}$ corrected calcium shown

\begin{tabular}{lcccc}
\hline Parameter & Total $(\mathrm{n}=183)$ & Survivor (121) & Died (62) & $\mathrm{P}$ \\
\hline Age (years) & $64.9(53.1$ to 72.5$)$ & $60.2(48.3$ to 69.4$)$ & $70.1(63.8$ to 76.7$)$ & $<0.001$ \\
Years on Dialysis & $1.39(0.46$ to 3.80$)$ & $1.06(0.43$ to 3.9$)$ & $1.6(0.49$ to 3.3$)$ & 0.72 \\
Access, Fistula (\%) & $174(95.1)$ & $113(93.39)$ & $61(98.4)$ & 0.14 \\
Gender, Male (\%) & $124(67.8)$ & $83(68.6)$ & $41(66.1)$ & 0.74 \\
Smoker (\%) & $120(65.6)$ & $73(60.3)$ & $47(75.8)$ & 0.037 \\
B.S.A (kg/m²) & $1.91(1.7$ to 2.0) & $1.91(1.74$ to 2.03$)$ & $1.71(1.86$ to 2.01$)$ & 0.65 \\
Diabetes (\%) & $70(38.3)$ & $40(33.1)$ & $30(48.4)$ & 0.043 \\
CCF (\%) & $27(14.8)$ & $13(10.7)$ & $14(22.6)$ & 0.033 \\
MI (\%) & $20(10.9)$ & $8(6.6)$ & $12(19.4)$ & 0.009 \\
PVD (\%) & $19(10.4)$ & $11(9.1)$ & $8(12.9)$ & 0.42 \\
Stroke or TIA (\%) & $20(10.9)$ & $14(11.6)$ & $6(9.7)$ & 0.81 \\
Hypertension (\%) & $107(58.5)$ & $69(57.0)$ & $38(61.3)$ & 0.58 \\
Renal Tx (\%) & $21(11.5)$ & $20(16.5)$ & $1(1.6)$ & 0.003 \\
EPO (\%) & $39(21.3)$ & $29(24.0)$ & $10(16.1)$ & 0.22 \\
Venofer(\%) & $17(9.3)$ & $13(10.7)$ & $4(6.5)$ & 0.34 \\
Alphacalcidol (\%) & $81(44.3)$ & $52(43.0)$ & $29(46.8)$ & 0.62 \\
Aspirin (\%) & $100(54.6)$ & $66(54.5)$ & $34(54.8)$ & 0.97 \\
Statin (\%) & $117(63.9)$ & $71(58.7)$ & $46(74.2)$ & 0.039 \\
ACEi (\%) & $75(41.0)$ & $46(38.0)$ & $29(46.8)$ & 0.25 \\
Beta Blocker (\%) & $83(45.4)$ & $53(43.8)$ & $30(48.4)$ & 0.56 \\
Albumin (g/L) & $39(36.6$ to 40.7$)$ & $39.7(37.3$ to 41.0$)$ & $37.6(35.0$ to 39.5$)$ & $<0.001$ \\
Haemoglobin g/L & $107.0(12.6)$ & $107.5(12.5)$ & $105(12.7)$ & 0.46 \\
Phosphate mg/dl & $1.54(0.44)$ & $1.57(0.40)$ & $1.5(0.51)$ & 0.41 \\
Potassium mmol/L & $4.8(0.59)$ & $4.8(0.57)$ & $4.691(0.6)$ & 0.34 \\
Sodium mmol/L & $137.5(2.51)$ & $137.9(2.2)$ & $136.7(2.9)$ & 0.007 \\
Systolic BP mmHg & $136.1(21.2)$ & $133(20.4)$ & $142.3(21.5)$ & 0.007 \\
Diastolic BP mmHg & $73.3(65.7$ to 81.7$)$ & $75.2(67.4$ to 81.9$)$ & $71.4(63.8$ to 75.9$)$ & 0.032 \\
UF L & $2.12(0.76)$ & $2.20(0.74)$ & $2.06(0.79)$ & 0.25 \\
Follow up (days) & $925(565$ to 1173$)$ & $1006(670$ to 1286$)$ & $708(427$ to 1015$)$ & $<0.001$ \\
\hline & & & &
\end{tabular}




\section{Kidney Blood Pressure Research}

Fig. 2. Univariate Kaplan Meir survival curves for patients with above versus below median baseline peak systolic strain rate (respectively, less negative versus more negative than the median of $-0.86 \mathrm{~S}-1$ ).

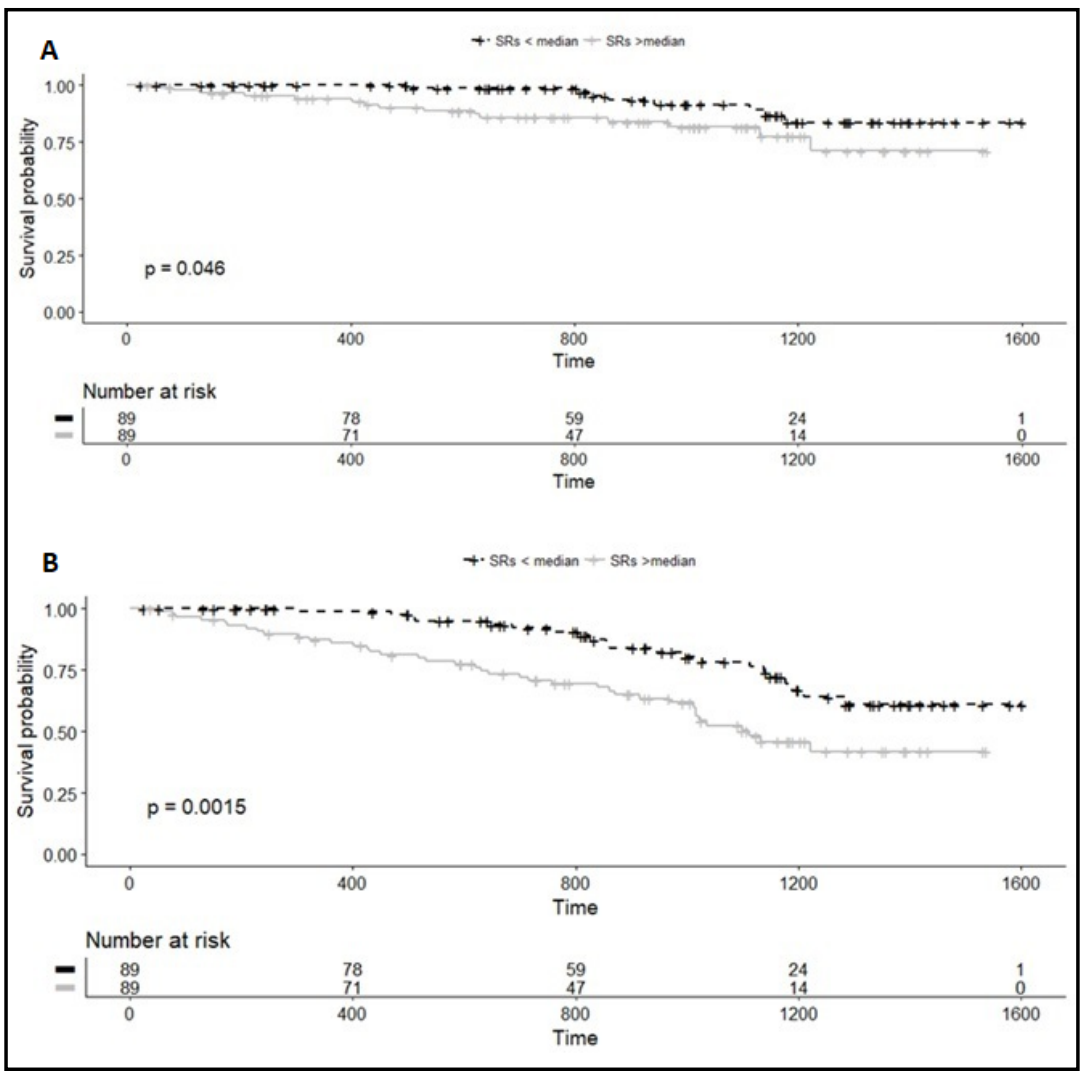

patient years at risk, and 27 patients suffered a heart failure episode with an incidence rate of heart failure episodes of 6.7 per 100 patient years at risk.

\section{Survival analyses}

Using the baseline median peak SRs (-0.86 $\mathrm{S}^{-1}$ ), a univariate KaplanMeier survival analysis was performed for allcause mortality and cardiovascular mortality. The survival analyses are shown in Fig. 2 . All demographic and e c h o c a r d i o g r a p h i c variables listed in Tables 1 and 2 were analysed using a univariate cox proportional hazards model for all-

Table 2. Baseline echocardiographic characteristics. Baseline echocardiographic characteristics for 183 patients with full data set. Also displayed is division across survivors and deaths. $\mathrm{E}=$ Peak $\mathrm{E}$ velocity. MV E/A =Early to late transmitral velocity ratio. E/e' Early transmitral velocity to tissue doppler mitral annular diastolic velocity ratio. $\mathrm{LAVI}=$ Left atrial volume index to height ${ }^{2.7}$. $\mathrm{LVMI}=$ left ventricular mass index to height ${ }^{2.7}, \mathrm{GLS}=$ Global Longitudinal strain, $\mathrm{SRs}=$ peak systolic strain rate, $\mathrm{P}=\mathrm{p}$ value. $\mathrm{MIV}=$ mitral inflow velocity. $\mathrm{LVH}=\mathrm{left}$ ventricular hypertrophy. Ef=Ejection fraction

\begin{tabular}{lcccc}
\hline Parameter & total (184) & Died (62) & Survivor (122) & P \\
\hline Biplane EF \% & $61.0(10.3))$ & $59.6(13.0)$ & $61.9(8.5)$ & 0.24 \\
Preserved EF (\%) & $137(74.4)$ & $39(62.9)$ & $98(80.3)$ & 0.01 \\
E cm/sec & $0.78(0.62$ to 0.97$)$ & $0.78(0.65$ to 1.07$)$ & $0.77(0.60$ to 0.95$)$ & 0.15 \\
E/e Ratio & $11.3(8.99$ to 16.2$)$ & $15.6(0.65$ to 20.0$)$ & $10.7(0.60$ to 14.5$)$ & 0.001 \\
MV E/A Ratio & $0.81(0.67$ to 1.10$)$ & $0.83(1.65$ to 1.1$)$ & $0.8(1.60$ to 1.1$)$ & 0.81 \\
EA TDI Ratio & $0.71(0.56$ to 0.98$)$ & $0.71(9.65$ to 0.92$)$ & $0.71(9.60$ to 0.99$)$ & 0.70 \\
LVMI g/m 2.7 & $50.6(40.5$ to 65.2$)$ & $50.6(0.65$ to 64.0$)$ & $50.7(0.38$ to 66.4$)$ & 0.34 \\
LAVI ml/m 2.7 & $14.2(11.5$ to 18.0$)$ & $14.3(12.1$ to 18.6$)$ & $13.9(10.9$ to 17.6$)$ & 0.22 \\
LVH \% & $101(54.9)$ & $36(58.0)$ & $58(52.3)$ & 0.21 \\
Strain analysis & & & & \\
GLS (\%) & $-14(-12.8$ to -16$)$ & $-14(-12.8$ to -16$)$ & $-15(-17$ to -12.8$)$ & 0.20 \\
SRs (S-1) & $-0.86(-1.00$ to -0.72$)$ & $-0.81(-0.92$ to -0.67$)$ & $-0.88(-1.03$ to -0.77) & 0.002 \\
Valvular disease & & & & \\
Aortic Stenosis & $7(3.8)$ & $4(6.4)$ & $3(2.5)$ & 0.22 \\
Mitral Stenosis & $1(0.55)$ & $0(0)$ & $1(0.8)$ & 1.00 \\
Mitral Regurg & $3(1.6)$ & $2(3.2)$ & $1(0.8)$ & 0.26 \\
Aortic Regurg & $5(2.7)$ & $4(6.5)$ & $1(0.8)$ & 0.04 \\
Tricuspid Regurg & $4(2.2)$ & $3(4.8)$ & $1(0.8)$ & 0.11 \\
\hline
\end{tabular}

cause mortality, cardiovascular death, MACE and heart failure episodes, and any parameter significant on univariate analysis was included in the multivariate analysis. An SR greater than $-0.86 \mathrm{~S}^{-1}$ (less negative) demonstrated a hazard ratio (HR) of 2.32 (1.36 to 3.95) in association with all-cause mortality after adjustment for EF, age, smoking history, MI, 


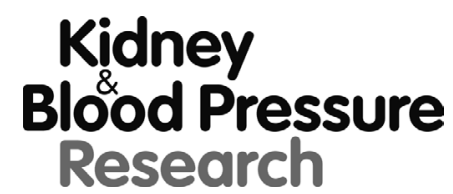

Kidney Blood Press Res 2018;43:1935-1942

\begin{tabular}{|l|l|l|}
\hline DOI: $10.1159 / 000496008$ & (c) 2018 The Author(s). Published by S. Karger AG, Basel \\
\hline
\end{tabular} Published online: 14 December 2018 www.karger.com/kbr

Hughes et al.: Strain Rate in Dialysis Patients

previous transplant, albumin and systolic blood pressure. An SR greater than $-0.86 \mathrm{~S}^{-1}$ (less negative) demonstrated an HR of 2.343 (0.99 to 5.553) $p=0.046$ for cardiovascular mortality after adjustment for EF, albumin and potassium. The only echocardiographic parameter independently associated with MACE was above median E/e (HR 2.09 [1.03 to 4.24], p=0.04). No echocardiographic parameter was statistically significantly associated with heart failure episodes. Full details of the multivariate models are found in Supplementary Table 1.

\section{Discussion}

Average peak Global longitudinal strain (GLS) did not differ between those who died and survivors. This is contrary to a previous analysis of GLS in the same cohort [29]. Similarly, to previous analysis of this cohort, systolic blood pressure, albumin, LVMI and EF correlated with GLS on univariate analysis. The associations identified were weak, and in a multivariate analysis only albumin and LVMI remained independently associated with GLS. LVMI was associated with an increase (i.e. less negative) GLS. This is likely as a result of LVH and stiffening of the LV as LVMI increases, reducing compliance and strain. Hypertension is a precursor to increased LVMI, and although correlated on univariate analysis systolic $\mathrm{BP}$ was not significant on univariate analysis. It is likely that LVMI and hypertension are not independent of each other, as elevated systolic blood pressure increases the strain on the cardiac myocyte, leading to hypertrophy and fibrosis, and an increase in LVMI. A lower serum albumin, is associated with a higher (less negative GLS) [29]. This may be as a result of inflammation, as a maker of MAI as discussed, leading to impaired cardiac structure or function, however its role, although very significant, and consistent is unclear. EF was inversely correlated with GLS, (-0.068 on univariate analysis), as EF increased, GLS became more negative, highlighting that these parameters are both measures of systolic function. Using survival analysis, no association was observed between GLS and survival to all-cause mortality, CV mortality, MACE or heart failure episodes. This differs to a previous analysis of the same cohort [29]. There are a number of possible reasons for this; this study was a longitudinal analysis of change in echocardiographic parameters over time, the same operator performed GLS analysis on the first, second and third year echocardiogram. This operator differed from the operator in previously published work. The intrauser and interuser variability was calculated with a Bland Altman analysis which showed a low variability. Secondly a longer period of follow up was available in this analysis, when the baseline GLS values published previously (obtained by DC) were used, a Wilcoxon test demonstrated no difference in GLS between the survivors and those who died in the whole cohort. This may indicate that GLS is of lesser value in forecasting long term survival.

Peak systolic strain rate, a parameter that has been analysed to a lesser extent than GLS, did differ between those who survived and those who died. There was a more rapid rate of LV deformation in survivors compared to those who died. This is consistent with results observed in a diabetic population and in a cohort of patients who have recently had a myocardial infarction [33], [34]. These suggest that SRs may have some role in identifying patients with subclinical myocardial dysfunction. GLS correlated with SRs, which would be expected, as a rapidly deforming ventricle is likely to deform to a greater degree during the cardiac cycle. SRs also correlated with E/e', where an increase in SRs (less negative) increased E/e'. Raised LV filling (represented by E/e') pressures are caused by a hypertrophied, stiffened LVH. It is likely that the same process of fibrosis and stiffening is causing a reduction in the rate of deformation of the LV during systole and during diastole to increased LV filling pressures and increase in Av E/e.

This is the first study to demonstrate SRs having a statistically significant association with adverse outcome in the general or dialysis population. It is of interest that SRs outperformed EF in both analyses suggesting that, in the dialysis cohort, strain analysis is of more importance than traditional echocardiographic parameters. The HR was slightly 


\section{Kidney \\ Blood Pressure Research}

higher for cardiovascular death, which would be expected as a number of patients died from infection, cancer and withdrawal from dialysis, which would likely be less strongly associated with myocardial deformation.

\section{Disclosure Statement}

The authors declare no conflicts of interest.

\section{References}

1 Lindner A, Charra B, Sherrard DJ, Scribner BH: Accelerated Atherosclerosis in Prolonged Maintenance Hemodialysis. N Engl J Med 1974;290:697-701.

-2 Longenecker JC, Coresh J, Powe NR, Levey AS, Fink NE, Martin A, Klag MJ: Traditional cardiovascular disease risk factors in dialysis patients compared with the general population: the CHOICE Study. J Am Soc Nephrol 2002;13:1918-1927.

- 3 Cheung AK, Sarnak MJ, Yan G, Berkoben M, Heyka R, Kaufman A, Lewis J, Rocco M, Toto R, Windus D, Ornt D, Levey AS; HEMO Study Group: Cardiac diseases in maintenance hemodialysis patients: Results of the HEMO Study. Kidney Int 2004;65:2380-2389.

- 4 Parfrey PS, Foley RN, Harnett JD, Kent GM, Murray DC, Barre PE: Outcome and risk factors for left ventricular disorders in chronic uraemia. Nephrol Dial Transplant 1996;11:1277-1285.

-5 Foley RN, Parfrey PS, Sarnak MJ: Epidemiology of cardiovascular disease in chronic renal disease. J Am Soc Nephrol 1998;9:S16-23.

-6 Ansari A, Kaupke CJ, Vaziri ND, Miller R, Barbari A: Cardiac pathology in patients with end-stage renal disease maintained on hemodialysis. Int J Artif Organs 1993;16:31-36.

7 Clyne N, Lins LE, Pehrsson SK: Occurrence and significance of heart disease in uraemia. An autopsy study. Scand J Urol Nephrol 1986;20:307-311.

-8 Jungers P, Massy ZA, Khoa TN, Fumeron C, Labrunie M, Lacour B, Descamps-Latscha B, Man NK: Incidence and risk factors of atherosclerotic cardiovascular accidents in predialysis chronic renal failure patients: a prospective study. Nephrol Dial Transplant 1997;12:2597-2602.

-9 Parfrey PS, Harnett JD, Barre PE: The natural history of myocardial disease in dialysis patients. J Am Soc Nephrol 1991;2:2-12.

10 Parfrey PS, Harnett JD, Griffiths SM, Gault MH, Barre PE: Congestive Heart Failure in Dialysis Patients. Arch Intern Med 1988;148:1519.

-11 Ikram H, Lynn KL, Bailey RR, Little PJ, Lynn K: Cardiovascular changes in chronic hemodialysis patients. Kidney Int 1983;24:371-376.

12 Rostand SG, Kirk KA, Rutsky EA: Dialysis-associated ischemic heart disease: Insights from coronary angiography. Kidney Int 1984;25:653-659.

13 Wanner C, Krane V, März W, Olschewski M, Mann JF, Ruf G, Ritz E; German Diabetes and Dialysis Study Investigators: Atorvastatin in Patients with Type 2 Diabetes Mellitus Undergoing Hemodialysis. N Engl J Med 2005;353:238-248.

14 Fellström BC, Jardine AG, Schmieder RE, Holdaas H, Bannister K, Beutler J, Chae DW, Chevaile A, Cobbe SM, Grönhagen-Riska C, de Lima JJ, Lins R, Mayer G, McMahon AW, Parving HH, Remuzzi G, Samuelsson O, Sonkodi S, Sci D, Süleymanlar G, et al.: Rosuvastatin and cardiovascular events in patients undergoing hemodialysis. N Engl J Med 2009;360:1395-1407.

15 Kalantar-Zadeh K, Block G, Humphreys MH, Kopple JD: Reverse epidemiology of cardiovascular risk factors in maintenance dialysis patients. Kidney Int 2003;63:793-808.

-16 Zoccali C, Benedetto FA, Mallamaci F, Tripepi G, Giacone G, Stancanelli B, Cataliotti A, Malatino LS: Left ventricular mass monitoring in the follow-up of dialysis patients: Prognostic value of left ventricular hypertrophy progression. Kidney Int 2004;65:1492-1498.

17 Foley RN, Parfrey PS, Harnett JD, Kent GM, Martin CJ, Murray DC, Barre PE: Clinical and echocardiographic disease in patients starting end-stage renal disease therapy. Kidney Int 1995;47:186-192. 


\section{Kidney \\ Blood Pressure Research}

Hughes et al.: Strain Rate in Dialysis Patients

18 Barberato SH, Bucharles SGE, Sousa AM, Costantini CO, Costantini CRF, Pecoits-Filho R: Prevalência e impacto prognóstico da disfunção diastólica na doença renal crônica em hemodiálise. Arq Bras Cardiol 2010;94:457-462.

19 Green D, Kalra PR, Kalra PA: Echocardiographic abnormalities in dialysis patients with normal ejection fraction. Nephrol Dial Transplant 2012;27:4256-4259.

-20 Yamada S, Ishii H, Takahashi H, Aoyama T, Morita Y, Kasuga H, Kimura K, Ito Y, Takahashi R, Toriyama T, Yasuda Y, Hayashi M, Kamiya H, Yuzawa Y, Maruyama S, Matsuo S, Matsubara T, Murohara T: Prognostic value of reduced left ventricular ejection fraction at start of hemodialysis therapy on cardiovascular and all-cause mortality in end-stage renal disease patients. Clin J Am Soc Nephrol 2010;5:1793-1798.

21 London GM: Cardiovascular disease in chronic renal failure: pathophysiologic aspects. Semin Dial 2003;16:85-94.

22 Matsubara Y, Kimachi M, Fukuma S, Onishi Y, Fukuhara S, Andreucci V: Development of a new risk model for predicting cardiovascular events among hemodialysis patients: Population-based hemodialysis patients from the Japan Dialysis Outcome and Practice Patterns Study (J-DOPPS). PLoS One 2017;12:e0173468.

23 Chiu DYY, Green D, Abidin N, Sinha S, Kalra PA: Cardiac imaging in patients with chronic kidney disease. Nat Rev Nephrol 2015;11:207-220.

24 Dandel M, Lehmkuhl H, Knosalla C, Suramelashvili N, Hetzer R: Strain and strain rate imaging by echocardiography - basic concepts and clinical applicability. Curr Cardiol Rev 2009;5:133-148.

25 Liu YW, Su CT, Huang YY, Yang CS, Huang JW, Yang MT, Chen JH, Tsai WC: Left ventricular systolic strain in chronic kidney disease and hemodialysis patients. Am J Nephrol 2011;33:84-90.

26 Smiseth OA, Torp H, Opdahl A, Haugaa KH, Urheim S: Myocardial strain imaging: how useful is it in clinical decision making? Eur Heart J 2016;37:1196-1207.

27 London GM: Left ventricular alterations and end-stage renal disease. Nephrol Dial Transpl 2002;17:29-36.

-28 Locatelli F, Bommer J, London GM, Martín-Malo A, Wanner C, Yaqoob M, Zoccali C: Cardiovascular disease determinants in chronic renal failure: clinical approach and treatment. Nephrol Dial Transpl 2001;16:459468.

29 Chiu D, Abidin N, Johnstone L, Chong M, Kataria V, Sewell J, Sinha S, Kalra PA, Green D: Novel Approach to Cardiovascular Outcome Prediction in Haemodialysis Patients. Am J Nephrol 2016;43:143-152.

-30 Lang RM, Badano LP, Mor-Avi V, Afilalo J, Armstrong A, Ernande L, Flachskampf FA, Foster E, Goldstein SA, Kuznetsova T, Lancellotti P, Muraru D, Picard MH, Rietzschel ER, Rudski L, Spencer KT, Tsang W, Voigt JU: Recommendations for Cardiac Chamber Quantification by Echocardiography in Adults: An Update from the American Society of Echocardiography and the European Association of Cardiovascular Imaging. J Am Soc Echocardiogr 2015;28:1-39.

31 Zoccali C, Benedetto FA, Mallamaci F, Tripepi G, Giacone G, Cataliotti A, Seminara G, Stancanelli B, Malatino LS; CREED Investigators: Prognostic impact of the indexation of left ventricular mass in patients undergoing dialysis. J Am Soc Nephrol 2001;12:2768-2774.

32 R Core Team: R, a language and environment for statistical computing. R Foundation for Statistical Computing, Vienna, Austria 2014. URL: http://www.R-project.org/.

-33 Ng AC, Delgado V, Bertini M, van der Meer RW, Rijzewijk LJ, Shanks M, Nucifora G, Smit JW, Diamant M, Romijn JA, de Roos A, Leung DY, Lamb HJ, Bax JJ: Findings from Left Ventricular Strain and Strain Rate Imaging in Asymptomatic Patients With Type 2 Diabetes Mellitus. Am J Cardiol 2009;104:1398-1401.

-34 Ersbøll M, Andersen MJ, Valeur N, Mogensen UM, Fakhri Y, Thune JJ, Møller JE, Hassager C, Søgaard P, Køber L: Early diastolic strain rate in relation to systolic and diastolic function and prognosis in acute myocardial infarction: a two-dimensional speckle-tracking study. Eur Heart J 2014;35:648-656. 